\title{
Minimally invasive and endoscopic versus open necrosectomy for necrotising pancreatitis: a pooled analysis of individual data for 1980 patients
}

\author{
Sandra van Brunschot, ${ }^{1}$ Robbert A Hollemans, ${ }^{2,3}$ Olaf J Bakker, ${ }^{4}$ Marc G Besselink, ${ }^{2}$ \\ Todd H Baron, ${ }^{5}$ Hans G Beger, ${ }^{6}$ Marja A Boermeester, ${ }^{2}$ Thomas L Bollen, ${ }^{7}$ \\ Marco J Bruno, ${ }^{8}$ Ross Carter, ${ }^{9}$ Jeremy J French, ${ }^{10}$ Djalma Coelho, ${ }^{11}$ Björn Dahl, ${ }^{12}$ \\ Marcel G Dijkgraaf, ${ }^{13}$ Nilesh Doctor, ${ }^{14}$ Peter J Fagenholz, ${ }^{15}$ Gyula Farkas, $^{16}$ \\ Carlos Fernandez del Castillo, ${ }^{15}$ Paul Fockens, ${ }^{1}$ Martin L Freeman, ${ }^{17}$ \\ Timothy B Gardner, ${ }^{18}$ Harry van Goor, ${ }^{19}$ Hein G Gooszen, ${ }^{20}$ Gerjon Hannink, ${ }^{21}$ \\ Rajiv Lochan, ${ }^{10}$ Colin J McKay, ${ }^{9}$ John P Neoptolemos, ${ }^{22}$ Atilla Oláh, ${ }^{23}$ \\ Rowan W Parks, ${ }^{24}$ Miroslav P Peev, ${ }^{15}$ Michael Raraty, ${ }^{22}$ Bettina Rau, ${ }^{25}$ Thomas Rösch, ${ }^{26}$ \\ Maroeska Rovers, ${ }^{20}$ Hans Seifert, ${ }^{12}$ Ajith K Siriwardena, ${ }^{27}$ Karen D Horvath, ${ }^{28}$ \\ Hjalmar C van Santvoort ${ }^{4,29}$
}

- Additional material is published online only. To view please visit the journal online (http://dx.doi.org/10.1136/ gutjnl-2016-313341).

For numbered affiliations see end of article.

\section{Correspondence to} Hjalmar C van Santvoort, Department of Surgery, Dutch Acute Pancreatitis Study Group, University Medical Center Utrecht $3508 \mathrm{GA} / \mathrm{St}$. Antonius Hospital Nieuwegein 3435 CM, The Netherlands; $h$. vanSantvoort@umcutrecht.nl

SB and RAH are shared first author.

Received 1 November 2016 Revised 8 June 2017 Accepted 9 June 2017 Published Online First 3 August 2017 gutjnl-2017-314660

Check for updates

To cite: van Brunschot $S$ Hollemans RA, Bakker OJ, et al. Gut 2018;67:697-706.

\begin{abstract}
Objective Minimally invasive surgical necrosectomy and endoscopic necrosectomy, compared with open necrosectomy, might improve outcomes in necrotising pancreatitis, especially in critically ill patients. Evidence from large comparative studies is lacking.

Design We combined original and newly collected data from 15 published and unpublished patient cohorts (51 hospitals; 8 countries) on pancreatic necrosectomy for necrotising pancreatitis. Death rates were compared in patients undergoing open necrosectomy versus minimally invasive surgical or endoscopic necrosectomy. To adjust for confounding and to study effect modification by clinical severity, we performed two types of analyses: logistic multivariable regression and propensity score matching with stratification according to predicted risk of death at baseline (low: $<5 \%$; intermediate: $\geq 5 \%$ to $<15 \%$; high: $\geq 15 \%$ to $<35 \%$; and very high: $\geq 35 \%$ ).
\end{abstract}

Results Among 1980 patients with necrotising pancreatitis, 1167 underwent open necrosectomy and 813 underwent minimally invasive surgical $(n=467)$ or endoscopic $(n=346)$ necrosectomy. There was a lower risk of death for minimally invasive surgical necrosectomy $(\mathrm{OR}, 0.53 ; 95 \% \mathrm{Cl} 0.34$ to $0.84 ; p=0.006)$ and endoscopic necrosectomy (OR, 0.20; $95 \% \mathrm{Cl} 0.06$ to $0.63 ; p=0.006)$. After propensity score matching with risk stratification, minimally invasive surgical necrosectomy remained associated with a lower risk of death than open necrosectomy in the very high-risk group (42/111 vs 59/111; risk ratio, $0.70 ; 95 \% \mathrm{Cl} 0.52$ to 0.95 ; $\mathrm{p}=0.02$ ). Endoscopic necrosectomy was associated with a lower risk of death than open necrosectomy in the high-risk group (3/40 vs $12 / 40$; risk ratio, $0.27 ; 95 \% \mathrm{Cl} 0.08$ to 0.88 ; $\mathrm{p}=0.03$ ) and in the very high-risk group (12/57 vs 28/57; risk ratio, $0.43 ; 95 \% \mathrm{Cl} 0.24$ to $0.77 ; p=0.005$ ).

Conclusion In high-risk patients with necrotising pancreatitis, minimally invasive surgical and endoscopic necrosectomy are associated with reduced death rates compared with open necrosectomy.

\section{INTRODUCTION}

Approximately $20 \%$ of patients with acute pancreatitis develop necrosis of the pancreas and peripancreatic tissue. ${ }^{1}$ These patients have a prolonged disease course with a high risk of complications such as multiple organ failure, secondary infection of the necrosis and death. ${ }^{12}$ Many patients with necrotising pancreatitis ultimately need to undergo pancreatic necrosectomy. ${ }^{1-4}$

Death rates after pancreatic necrosectomy recently reported by international specialist centres vary from $0 \%$ to $25 \% .^{5-12}$ This variation may be explained by differences in case-mix or by differences in treatment strategies and local expertise. Several changes in the treatment of patients with necrotising pancreatitis have occurred over the last 20 years. First, the timing of intervention has shifted from very early in the disease course to around 3-4 weeks after onset of symptoms. ${ }^{3413}$ Second, the indication for necrosectomy has changed from sterile necrosis to predominantly infected necrosis. ${ }^{3414}$ Third, percutaneous or endoscopic drainage of the necrotic collection is now often the first step in treatment before necrosectomy. ${ }^{15}$ Finally, as an alternative to open necrosectomy, minimally invasive surgical necrosectomy and the even less invasive endoscopic necrosectomy are increasingly being performed. ${ }^{7-10} 12$

Minimally invasive necrosectomy is thought to be beneficial in the acute phase by inducing less surgical stress, thereby lowering the proinflammatory response, especially in already critically ill patients. ${ }^{1617}$ Another advantage is the avoidance of the long-term morbidity of a large abdominal incision. Studies that directly compare minimally invasive necrosectomy with open necrosectomy for primary clinical outcomes are scarce. A few retrospective studies have been performed, but 
Significance of this study

\section{What is already known on this subject?}

- In patients with infected necrotising pancreatitis, endoscopic or percutaneous catheter drainage of the necrotic collection as a first step is now considered standard treatment.

- Patients in whom drainage alone does not lead to clinical recovery need to undergo a more invasive necrosectomy procedure.

- Minimally invasive surgical necrosectomy and endoscopic necrosectomy are gaining popularity over open necrosectomy. There is, however, no clear evidence from large comparative studies with clinical endpoints in favour of minimally invasive techniques. As a result, open necrosectomy is still an option in treatment guidelines, and observational studies on open necrosectomy continue to be published.

- A randomised trial comparing minimally invasive surgical or endoscopic necrosectomy with open necrosectomy with death as primary endpoint will most likely never be performed.

\section{What are the new findings?}

- This study included 1980 patients who underwent necrosectomy for acute necrotising pancreatitis in 51 hospitals across 8 countries worldwide.

- Detailed individual patient data were collected, and patients undergoing minimally invasive necrosectomy were compared with patients undergoing open necrosectomy for the primary endpoint of in-hospital death.

- To adjust for potential confounding and to study effect modification by clinical severity, thorough statistical analyses included multivariable regression modelling and propensity score matching with stratification according to prenecrosectomy risk of death.

- Minimally invasive surgical and endoscopic necrosectomy were associated with lower death rates than open necrosectomy in patients who were severely ill at time of necrosectomy.

How might it impact on clinical practice in the foreseeable future?

- This study combined individual patient data from leading pancreatic specialist centres worldwide to form the largest known cohort of patients undergoing pancreatic necrosectomy. Even after adjusting for potential confounding by several methods, minimally invasive necrosectomy reduced mortality in the most severely ill patients. These findings suggest that treatment guidelines should discourage the open approach as initial treatment in patients with infected necrotising pancreatitis in need of necrosectomy.

these were mostly small and hampered by selection bias and confounding. ${ }^{12} 18$ The only available randomised trial included only 20 patients. ${ }^{17}$ Despite the lack of evidence in favour of minimally invasive surgical and endoscopic necrosectomy, these techniques are increasingly popular in the treatment of necrotising pancreatitis. This, combined with the fact that necrotising pancreatitis is a complex and relatively rare disease, makes it unlikely that a trial with a sufficiently large sample size to study mortality will ever be performed. It therefore remains unclear if minimally invasive necrosectomy methods reduce death rates, especially in the context of other recent changes in the treatment of necrotising pancreatitis. As a result, open necrosectomy remains a valid option and is still practised worldwide. ${ }^{311} 1920$

In this international collaborative project, we combined original patient data from published and unpublished cohorts on pancreatic necrosectomy in specialist centres worldwide. We compared death rates of open necrosectomy with minimally invasive surgical and endoscopic necrosectomy in a large number of patients. This allowed for several approaches to adjust for confounding and to study effect modification by clinical severity. We hypothesised that minimally invasive necrosectomy reduced death rates.

\section{METHODS}

\section{Study design}

We combined original study data from patients undergoing pancreatic necrosectomy in 51 hospitals who were included in 15 cohorts from specialist pancreatic centres in the USA and Canada $(n=4)$, UK $(n=4)$, Germany $(n=2)$, Hungary $(n=2)$, The Netherlands $(n=1)$, India $(n=1)$ and Brazil $(n=1)$. The cohorts were identified by a predefined systematic literature search. A total of 13 cohorts were published previously. ${ }^{6-10} 19{ }^{21-27}$ For four of these cohorts, ${ }^{71019} 24$ additional patients were included of whom the data were unpublished and two cohorts consist of entirely unpublished data. Details on the search, eligibility criteria, included cohorts and quality assessment/risk of bias of individual studies are available in the online supplementary appendix (p4-5). Once the corresponding author of a cohort agreed to participate, case record forms containing original and additional individual patient data regarding baseline characteristics, method of intervention and clinical outcomes were collected. All data were anonymised. The institutional review boards of the participating centres approved study protocols, if appropriate. The study design was predefined and prospectively registered (www. crd.york.ac.uk/PROSPERO: CRD42014008995). We adhered to the STROBE guidelines (The Strengthening the Reporting of Observational Studies in Epidemiology) and the PRISMA-IPD guidelines (Preferred Reporting Items for Systematic Reviews and Meta-Analyses for Individual Patient Data). ${ }^{28} 29$

\section{Data collection}

Data were collected in a standardised manner using an electronic case record form. The following baseline variables were collected: sex, age, tertiary referral, cause of pancreatitis, catheter drainage before necrosectomy, time from hospital admission to necrosectomy, Acute Physiology and Chronic Health Evaluation II (APACHE-II) score and organ failure $\leq 24$ hours before necrosectomy, documented infection of necrosis, and year of necrosectomy. Method of necrosectomy (ie, open necrosectomy, minimally invasive surgical necrosectomy or endoscopic necrosectomy), complications and death were also recorded. Further details on data collection and definitions of variables are provided in the online supplementary appendix (p5-6).

Data were checked for consistency and plausibility. Data were missing in 8 of the 13 baseline variables, with a range of $0.2 \%-$ 4.7\%. Missing data were imputed by multiple imputation using chained equations. More information on missing data and imputation is available in the online supplementary appendix (p6-7).

\section{Statistical analysis}

Patients undergoing open necrosectomy were compared with patients undergoing minimally invasive surgical necrosectomy and with patients undergoing endoscopic necrosectomy. The 
primary endpoint was in-hospital death during index admission. Readmissions within 10 days after discharge from index admission were considered as part of the index admission. Patients were analysed according to the intention-to-treat principle. We anticipated that certain prognostic baseline variables that are associated with death, such as measures of disease severity, would not be evenly distributed among treatment groups. This could be due to selection bias in the individual cohorts or because clinical severity played a role in deciding which method of necrosectomy was performed (ie, confounding by indication or confounding by severity). ${ }^{30}$ To adjust for confounding and to explore effect modification by clinical severity, we performed two main analyses.

The first main analysis was a multivariable logistic regression analysis to evaluate the association between different methods of necrosectomy and death. Formation of a directed acyclic graph was used to aid selection of covariates to be included in the model (see online supplementary appendix $(p 7,13)) .{ }^{31}$ The following factors were included as covariates: age, documented infected necrosis, study cohort, time since hospital admission, year of necrosectomy and severity of disease parameters within 24 hours of necrosectomy, and APACHE-II score, cardiovascular failure, pulmonary failure and renal failure. To study the effect of disease severity as a modifier on the outcome, we performed a secondary analysis in which an interaction term for severity with method of necrosectomy was added to the final multivariable model. We chose the APACHE-II score at time of necrosectomy (ie, APACHE $<7, \geq 7$ to $<11, \geq 11$ to $<15$, and $\geq 15$ ) as the disease severity indicator in these analyses because it is a composite of clinical and laboratory parameters indicative of disease severity at a specific point in time. ${ }^{32}$

The second main analysis was a propensity score-matched analysis with risk stratification. Recognising severity of disease as a possible effect modifier (ie, the beneficial effect of minimally invasive necrosectomy is greater in more severely ill patients), all patients were stratified according to their predicted risk of death at baseline. To accomplish this, a prediction model for the risk of death determined at baseline (ie, within 24 hours before necrosectomy) was developed using the data from patients undergoing open necrosectomy (ie, the control group). ${ }^{33}$ First, the univariable association was determined between death and all of the following baseline characteristics: study cohort, sex, age, year of necrosectomy, cause of pancreatitis, tertiary referral, catheter drainage before necrosectomy, documented infected necrosis, time since hospital admission and severity of disease parameters within 24 hours of necrosectomy, APACHE-II score, cardiovascular failure, pulmonary failure and renal failure. All factors with $\mathrm{p}<0.1$ were included in a multivariable regression analysis, with forced entry of sex and infected necrosis (ie, a variable hypothesised to have major prognostic value). Variables were excluded using stepwise backward elimination $(p>0.05)$. Variables that remained independently associated with death in the multivariable model were study cohort, age, APACHE-II score, cardiovascular failure, pulmonary failure and renal failure. Performance of the model was very good with an area under the curve of 0.85 . We chose this method as opposed to classifying severity of pancreatitis in general by the recently revised Atlanta classification $^{1}$ or the determinant-based classification of acute pancreatitis severity ${ }^{34}$ because we specifically wanted to determine disease severity at the time of necrosectomy.

Using this model, patients in each treatment group were assigned to one of four baseline categories of predicted risk of death: low $(<5 \%)$; intermediate $(\geq 5 \%$ to $<15 \%)$; high $(\geq 15 \%$ to $<35 \%)$; or very high $(\geq 35 \%)$. Further details on the prediction model and risk stratification are available in the online supplementary appendix (p7). Within the four risk groups, patients were matched using their propensity score to create cohorts of patients with similar baseline characteristics. The propensity score is the probability of treatment assignment conditional on observed baseline characteristics and allows one to design and analyse an observational study so that it mimics some of the characteristics of a randomised trial. ${ }^{35}$ We developed a non-parsimonious multivariable logistic regression model to estimate a propensity score for minimally invasive surgical necrosectomy and endoscopic necrosectomy. This included study cohort as a cofactor to adjust for potential hidden confounders (eg, better supportive intensive care in more recent years). Details of the individual variables included in the model are provided in the online supplementary appendix (p8). Patients undergoing minimally invasive surgical necrosectomy or endoscopic necrosectomy were matched $1: 1$ with patients undergoing open necrosectomy using their propensity score with the nearest neighbour matching algorithm without replacement (a calliper width equal to 0.2 of the SD of the logit score was used). Standardised differences were estimated for all the baseline covariates to assess imbalance before matching and balance after matching. A standardised difference of less than 10\% indicates appropriate balance. ${ }^{35}$

Results of multivariable regression analysis are given as ORs and 95\% CIs. Differences in death rates were tested with the McNemar's test for paired data in the matched cohorts. Comparisons of death rates are presented as risk ratios. All tests were two-tailed and $\mathrm{p}$ values of less than 0.05 were considered statistically significant.

Predefined subgroup analyses were performed for patients with infected necrosis and for patients who underwent previous catheter drainage. Several other sensitivity analyses were performed in the comparison of minimally invasive necrosectomy and open necrosectomy (see online supplementary appendix (p8)). We also compared endoscopic necrosectomy with minimally invasive surgical necrosectomy on the primary outcome death using propensity score matching and risk stratification.

\section{RESULTS}

\section{Study population}

We included 1980 patients who underwent pancreatic necrosectomy; a total of 1167 patients underwent open necrosectomy, 467 patients underwent minimally invasive surgical necrosectomy and 346 patients underwent endoscopic necrosectomy. Baseline characteristics for the entire study population and per study cohort are presented in the online supplementary appendix (p21-23). A total of 325 out of 1980 patients (16\%) in the study died during index admission.

\section{Logistic regression adjusted analysis}

While adjusting for confounders (ie. cohort, age, documented infected necrosis, study cohort, time since hospital admission, year of necrosectomy and severity of disease parameters within 24 hours of necrosectomy, APACHE-II score, cardiovascular failure, pulmonary failure and renal failure), method of necrosectomy was significantly associated with death (see online supplementary appendix (p24). Compared with open necrosectomy, minimally invasive surgical necrosectomy displayed an OR of 0.53 (95\% CI 0.34 to $0.84 ; \mathrm{p}=0.006$ ), and endoscopic necrosectomy an OR of 0.20 (95\% CI 0.06 to 0.63 ; $\mathrm{p}=0.006)$.

Inclusion of the interaction term 'disease severity (APACHE-II score) by method of necrosectomy' showed that endoscopic 
necrosectomy was associated with less mortality irrespective of the APACHE-II score (OR 0.13; 95\% CI 0.02 to $0.95 ; \mathrm{p}=0.04$ ). The interaction term 'APACHE-II score by minimally invasive surgical necrosectomy' confirmed that clinical severity is an effect modifier, as minimally invasive surgical necrosectomy only remained associated with less mortality in patients with the highest APACHE-II scores (OR 0.27; 95\% CI 0.08 to 0.88 ; $\mathrm{p}=0.03)$. Detailed results of this secondary regression analyses are provided in the online supplementary appendix (p25).

\section{Propensity score-matched analysis with risk stratification}

Using a multivariable prediction model (see online supplementary appendix (p26)), patients were stratified according to their predicted risk of death at baseline. Stratification was considered successful because there were no major differences in predicted risk of death for patients undergoing open necrosectomy, minimally invasive surgical necrosectomy and endoscopic necrosectomy, respectively: low-risk group: median 2\% (IQR, 1\%-3\%) vs median 3\% (IQR, 0\%-4\%) vs median 4\% (IQR, 2\%-4\%); intermediate-risk group: median 9\% (IQR, 7\%-11\%) vs median 9\% (IQR, 7\%-12\%) vs median 10\% (IQR, 8\%-12\%); high-risk group: median 24\% (IQR, 18\%-29\%) vs median 22\% (IQR, 19\%-29\%) vs median 22\% (IQR, 19\%-27\%); and very highrisk group: median 52\% (IQR, 43\%-64\%) vs median 58\% (IQR, 45\%-78\%) vs 51\% (IQR, 42\%-72\%).

Subsequently, a total of 376 patients who underwent minimally invasive surgical necrosectomy were matched with 376 patients who underwent open necrosectomy, and a total of 198 patients who underwent endoscopic necrosectomy were matched with 198 patients who underwent open necrosectomy. Baseline characteristics in each risk group for unmatched and matched cohorts are presented in tables 1 and 2 . In the unmatched cohorts, although predicted risk of death was similar within each of the four risk groups, significant imbalance in individual baseline characteristics remained after risk stratification, as indicated by standardised mean differences greater than $10 \%$. The matched cohorts were well balanced for all baseline characteristics because none of the standardised differences exceeded $10 \%$. There was sufficient overlap in propensity scores as is shown in the online supplementary appendix figures 4 and 5 .

Actual death rates in the matched cohorts in each risk group are shown in figure 1. Minimally invasive surgical necrosectomy was associated with a lower risk of death than open necrosectomy in the very high-risk group (risk ratio $0.70 ; 95 \%$ CI 0.52 to $0.95 ; \mathrm{p}=0.02)$. Endoscopic necrosectomy was associated with a lower risk of death than open necrosectomy in the highrisk group (risk ratio $0.27 ; 95 \%$ CI 0.08 to $0.88 ; \mathrm{p}=0.03$ ) and the very high-risk group (risk ratio $0.43 ; 95 \%$ CI 0.24 to 0.77 ; $\mathrm{p}=0.005)$, with judgement suspended in the intermediate-risk group (risk ratio $0.14 ; 95 \%$ CI 0.02 to $1.10 ; \mathrm{p}=0.06$ ).

\section{Subgroup and sensitivity analyses}

The propensity score-matched analysis was also performed in the subgroups of patients with documented infected necrosis (403 patients $(86 \%)$ in the minimally invasive surgical group, 197 patients $(57 \%)$ in the endoscopic group and 885 patients $(76 \%)$ in the open necrosectomy group) and in patients who underwent previous catheter drainage (436 patients $(93 \%)$ in the minimally invasive surgical group, 178 patients (51\%) in the endoscopic group and 210 patients $(18 \%)$ in the open necrosectomy group). Baseline characteristics for the unmatched and the matched cohorts and the actual death rates after matching are provided in the online supplementary appendix (p27-42). Results were in line with the primary analyses.

Exclusion of patients undergoing necrosectomy before 3 weeks (ie, <22 days) after admission from the matched cohorts resulted in loss of nearly half of all pairs in each of the two compared groups. Patients undergoing minimally invasive necrosectomy still had lower death rates, although statistical significance was no longer reached (see online supplementary appendix p59).

As alternative risk stratification, patients were stratified according to their APACHE-II score within 24 hours before necrosectomy (ie, $<7, \geq 7$ to $<11, \geq 11$ to $<15$, and $\geq 15$ ) and matched with propensity score matching (online supplementary appendix (p43-48)). Similar to the primary analyses, minimally invasive surgical necrosectomy and endoscopic necrosectomy were associated with a lower actual death rate in the higher APACHE-II groups (see online supplementary appendix (p49-50)).

In addition to death, other study outcomes included postoperative complications (ie, bleeding and pancreatic fistula), number of necrosectomies and hospital stay after necrosectomy. In the matched cohorts, bleeding occurred in 5\%-19\% of patients and was more frequent in the higher risk of death groups. There was no statistically significant difference for the complication bleeding between minimally invasive necrosectomy methods and open necrosectomy. Pancreatic fistula occurred in $4 \%-35 \%$ of patients, was more frequent in patients at lower risk of death and occurred more often in patients who underwent open necrosectomy. Overall, patients who underwent minimally invasive surgical necrosectomy had the longest hospital stay after necrosectomy (median over the four risk groups ranging from 32 to 59 days), followed by open necrosectomy (median ranging from 21 to 52 days) and endoscopic necrosectomy (median ranging from 5 to 42 days). The number of necrosectomies was highest in the endoscopic groups (median ranging from 3 to 4), followed by the minimally invasive surgical groups (median ranging from 2 to 3 ) and open necrosectomy groups (median 1). Detailed results with respect to all other outcomes in each risk group are provided in the online supplementary appendix (p51-54).

In our secondary comparison of endoscopic necrosectomy with minimally invasive surgical necrosectomy, 215 patient pairs were matched. Baseline characteristics before and after matching in each risk group are presented in the online supplementary appendix (p55-57). In the matched cohorts, the differences in death rates between the endoscopic groups and minimally invasive surgical groups were not statistically significant (see online supplementary appendix (p58)).

\section{DISCUSSION}

In this international collaborative study involving 1980 patients with necrotising pancreatitis from 51 hospitals across 8 countries, minimally invasive surgical necrosectomy or endoscopic necrosectomy compared with open necrosectomy significantly decreased mortality among high-risk patients. In contrast to meta-analyses which pool data directly from published results (ie, paper analysis), this study provides a combined analysis of original, individual patient data of previously published cohorts (including unpublished data from ongoing registries) and unpublished cohorts.

A large number of, mostly retrospective, cohort studies have reported outcomes of patients undergoing minimally invasive pancreatic necrosectomy. Few studies, however, have directly compared minimally invasive necrosectomy with open necrosectomy. One meta-analysis, based on paper analysis of four studies, 
Table 1 Baseline characteristics before and after propensity score matching of patients undergoing minimally invasive surgical necrosectomy or open necrosectomy*

\begin{tabular}{|c|c|c|c|c|c|c|}
\hline \multirow[t]{2}{*}{ Characteristics } & \multicolumn{3}{|l|}{ Before matching } & \multicolumn{3}{|l|}{ After matching } \\
\hline & $\begin{array}{l}\text { Minimally } \\
\text { invasive surgical } \\
\text { necrosectomy } \\
(\mathrm{n}=97)\end{array}$ & $\begin{array}{l}\text { Open } \\
\text { necrosectomy } \\
(n=377)\end{array}$ & $\begin{array}{l}\text { Standardised } \\
\text { difference (\%) }\end{array}$ & $\begin{array}{l}\text { Minimally } \\
\text { invasive surgical } \\
\text { necrosectomy } \\
(\mathrm{n}=87)\end{array}$ & $\begin{array}{l}\text { Open } \\
\text { necrosectomy } \\
(n=87)\end{array}$ & $\begin{array}{l}\text { Standardised } \\
\text { difference (\%) }\end{array}$ \\
\hline \multicolumn{7}{|l|}{ Low risk of death $(<5 \%)$} \\
\hline Male sex, n (\%) & $65(68)$ & $276(73)$ & 12.7 & $63(72)$ & $61(70)$ & 4.1 \\
\hline Age & $43 \pm 12$ & $44 \pm 13$ & 9.5 & $44 \pm 12$ & $45 \pm 14$ & 5.7 \\
\hline \multicolumn{7}{|l|}{ Cause, n (\%) } \\
\hline Gallstones & $50(51)$ & $111(29)$ & 46.2 & $40(46)$ & $38(44)$ & 5.5 \\
\hline Alcohol & $28(29)$ & $177(47)$ & 38.0 & $28(32)$ & $27(31)$ & 1.5 \\
\hline Other & $19(20)$ & $89(24)$ & 9.7 & $19(22)$ & $22(25)$ & 8.0 \\
\hline APACHE-II score $†$ & $6.0 \pm 3.4$ & $7.7 \pm 4.2$ & 47.0 & $6.3 \pm 3.4$ & $6.0 \pm 3.7$ & 6.3 \\
\hline Cardiovascular failure, $\mathrm{n}(\%) \dagger \ddagger$ & $0(0)$ & $7(2)$ & 19.7 & $0(0)$ & $0(0)$ & 0 \\
\hline Pulmonary failure, $\mathrm{n}(\%)+\S$ & $3(3)$ & $30(8)$ & 21.2 & $3(3)$ & $3(3)$ & 0.5 \\
\hline Renal failure, $\mathrm{n}(\%)+\emptyset$ & $2(2)$ & $10(3)$ & 4.2 & $2(2)$ & $2(2)$ & 3.9 \\
\hline Documented infected necrosis, $\mathrm{n}(\%)^{* *}$ & $88(91)$ & $279(74)$ & 47.0 & $79(90)$ & $79(90)$ & 0.6 \\
\hline Tertiary referral, n (\%) & $77(80)$ & $205(55)$ & 56.3 & $68(78)$ & $68(78)$ & 1.2 \\
\hline \multirow{2}{*}{$\begin{array}{l}\text { Time since hospital admission, } \\
\text { days }\end{array}$} & $56 \pm 53$ & $51 \pm 133$ & 5.2 & $56 \pm 54$ & $66 \pm 158$ & 7.6 \\
\hline & $\begin{array}{l}\text { Minimally } \\
\text { invasive surgical } \\
\text { necrosectomy } \\
(n=119)\end{array}$ & $\begin{array}{l}\text { Open } \\
\text { necrosectomy } \\
(n=343)\end{array}$ & $\begin{array}{l}\text { Standardised } \\
\text { difference (\%) }\end{array}$ & $\begin{array}{l}\text { Minimally } \\
\text { invasive surgical } \\
\text { necrosectomy } \\
(n=108)\end{array}$ & $\begin{array}{l}\text { Open } \\
\text { necrosectomy } \\
(n=108)\end{array}$ & $\begin{array}{l}\text { Standardised } \\
\text { difference (\%) }\end{array}$ \\
\hline \multicolumn{7}{|l|}{ Intermediate risk of death $(\geq 5 \%$ to $<15 \%)$} \\
\hline Male sex, n (\%) & $82(69)$ & $229(67)$ & 5.1 & $74(69)$ & $73(68)$ & 2.0 \\
\hline Age & $54 \pm 15$ & $53 \pm 14$ & 5.9 & $54 \pm 14$ & $55 \pm 13$ & 6.2 \\
\hline \multicolumn{7}{|l|}{ Cause, n (\%) } \\
\hline Gallstones & $65(55)$ & $139(40)$ & 29.2 & $56(52)$ & $53(49)$ & 5.3 \\
\hline Alcohol & $29(24)$ & $119(35)$ & 23.0 & $28(26)$ & $30(28)$ & 3.3 \\
\hline Other & $25(21)$ & $85(25)$ & 9.6 & $24(22)$ & $25(23)$ & 2.6 \\
\hline APACHE-II score $\dagger$ & $7.9 \pm 3.0$ & $10.0 \pm 4.1$ & 57.9 & $8.2 \pm 2.8$ & $8.1 \pm 3.5$ & 4.6 \\
\hline Cardiovascular failure, $\mathrm{n}(\%) \dagger \ddagger$ & $3(3)$ & $65(19)$ & 53.2 & $3(3)$ & $3(3)$ & 5.8 \\
\hline Pulmonary failure, $\mathrm{n}(\%)+\S$ & $8(7)$ & $113(33)$ & 68.1 & $8(8)$ & $6(6)$ & 8.4 \\
\hline Renal failure, $\mathrm{n}(\%)+\uparrow$ & $5(4)$ & $42(12)$ & 29.7 & $5(5)$ & $4(4)$ & 6.0 \\
\hline Documented infected necrosis, $\mathrm{n}(\%)^{* *}$ & $95(80)$ & $270(79)$ & 3.2 & $87(81)$ & $88(82)$ & 2.0 \\
\hline Tertiary referral, n (\%) & $95(80)$ & $208(61)$ & 43.3 & $84(78)$ & $82(76)$ & 4.3 \\
\hline \multirow{2}{*}{$\begin{array}{l}\text { Time since hospital admission, } \\
\text { days }\end{array}$} & $48 \pm 41$ & $30 \pm 27$ & 50.0 & $43 \pm 33$ & $41 \pm 36$ & 5.1 \\
\hline & $\begin{array}{l}\text { Minimally } \\
\text { invasive surgical } \\
\text { necrosectomy } \\
(n=120)\end{array}$ & $\begin{array}{l}\text { Open } \\
\text { necrosectomy } \\
(n=225)\end{array}$ & $\begin{array}{l}\text { Standardised } \\
\text { difference (\%) }\end{array}$ & $\begin{array}{l}\text { Minimally } \\
\text { invasive surgical } \\
\text { necrosectomy } \\
(n=70)\end{array}$ & $\begin{array}{l}\text { Open } \\
\text { necrosectomy } \\
(n=70)\end{array}$ & $\begin{array}{l}\text { Standardised } \\
\text { difference (\%) }\end{array}$ \\
\hline \multicolumn{7}{|l|}{ High risk of death $(\geq 15 \%$ to $<35 \%)$} \\
\hline Male sex, $\mathrm{n}(\%)$ & $65(54)$ & $140(62)$ & 17.5 & $43(61)$ & $44(63)$ & 4.1 \\
\hline Age & $57 \pm 13$ & $58 \pm 14$ & 7.1 & $59 \pm 13$ & $59 \pm 14$ & 4.2 \\
\hline \multicolumn{7}{|l|}{ Cause, n (\%) } \\
\hline Gallstones & $72(60)$ & $88(39)$ & 43.0 & $35(50)$ & $36(51)$ & 1.7 \\
\hline Alcohol & $31(25)$ & $81(36)$ & 23.2 & $21(30)$ & $21(30)$ & 0.6 \\
\hline Other & $17(15)$ & $56(25)$ & 26.3 & $14(20)$ & $13(19)$ & 3.0 \\
\hline APACHE-II score $†$ & $10.1 \pm 4.3$ & $12.8 \pm 4.2$ & 62.2 & $11.3 \pm 3.9$ & $11.2 \pm 3.5$ & 0.9 \\
\hline Cardiovascular failure, $\mathrm{n}(\%)+\ddagger$ & $25(21)$ & $98(44)$ & 51.2 & $20(29)$ & $22(31)$ & 4.3 \\
\hline Pulmonary failure, $\mathrm{n}(\%)+\S$ & $25(21)$ & $145(65)$ & 97.6 & $23(32)$ & $24(34)$ & 4.8 \\
\hline Renal failure, $\mathrm{n}(\%)+\uparrow$ & $7(6)$ & $65(29)$ & 64.7 & $7(10)$ & $7(10)$ & 2.8 \\
\hline Documented infected necrosis, $\mathrm{n}(\%)^{* *}$ & $97(81)$ & $182(81)$ & 0.5 & $60(85)$ & $61(87)$ & 3.3 \\
\hline Tertiary referral, n (\%) & $99(83)$ & $160(71)$ & 27.4 & $58(83)$ & $58(83)$ & 0.4 \\
\hline $\begin{array}{l}\text { Time since hospital admission, } \\
\text { days }\end{array}$ & $35 \pm 22$ & $24 \pm 19$ & 56.4 & $29 \pm 14$ & $29 \pm 22$ & 1.6 \\
\hline
\end{tabular}




\begin{tabular}{|c|c|c|c|c|c|c|}
\hline \multirow[t]{2}{*}{ Characteristics } & \multicolumn{3}{|l|}{ Before matching } & \multicolumn{3}{|l|}{ After matching } \\
\hline & $\begin{array}{l}\text { Minimally } \\
\text { invasive surgical } \\
\text { necrosectomy } \\
(n=131)\end{array}$ & $\begin{array}{l}\text { Open } \\
\text { necrosectomy } \\
(n=222)\end{array}$ & $\begin{array}{l}\text { Standardised } \\
\text { difference (\%) }\end{array}$ & $\begin{array}{l}\text { Minimally } \\
\text { invasive surgical } \\
\text { necrosectomy } \\
(n=111)\end{array}$ & $\begin{array}{l}\text { Open } \\
\text { necrosectomy } \\
(n=111)\end{array}$ & $\begin{array}{l}\text { Standardised } \\
\text { difference }(\%)\end{array}$ \\
\hline \multicolumn{7}{|l|}{ Very high risk of death $(\geq 35 \%)$} \\
\hline Male sex, n (\%) & $81(62)$ & $146(66)$ & 8.2 & $68(62)$ & $70(63)$ & 2.6 \\
\hline Age & $63 \pm 12$ & $62 \pm 14$ & 5.5 & $62 \pm 12$ & $63 \pm 13$ & 0.9 \\
\hline \multicolumn{7}{|l|}{ Cause, n (\%) } \\
\hline Gallstones & $74(56)$ & $99(44)$ & 23.7 & $62(56)$ & $66(60)$ & 7.3 \\
\hline Alcohol & $37(29)$ & $66(30)$ & 2.3 & $30(27)$ & $29(26)$ & 1.2 \\
\hline Other & $20(15)$ & $57(26)$ & 26.8 & $19(17)$ & $16(14)$ & 8.5 \\
\hline APACHE-II scoret & $16.8 \pm 5.7$ & $16.6 \pm 5.3$ & 3.3 & $17.0 \pm 5.7$ & $17.1 \pm 5.5$ & 1.2 \\
\hline Cardiovascular failure, $\mathrm{n}(\%) \dagger \ddagger$ & $91(69)$ & $179(81)$ & 25.9 & $81(74)$ & $84(76)$ & 5.8 \\
\hline Pulmonary failure, $\mathrm{n}(\%)+\S$ & $90(69)$ & $182(82)$ & 30.9 & $79(72)$ & $78(70)$ & 2.0 \\
\hline Renal failure, $\mathrm{n}(\%)+\emptyset$ & $59(45)$ & $123(55)$ & 21.0 & $53(48)$ & $50(45)$ & 4.4 \\
\hline Documented infected necrosis, $\mathrm{n}(\%)^{* *}$ & $123(94)$ & $154(69)$ & 67.3 & $103(93)$ & $105(95)$ & 7.5 \\
\hline Tertiary referral, $\mathrm{n}(\%)$ & $115(88)$ & $168(76)$ & 31.4 & $95(86)$ & $92(83)$ & 5.4 \\
\hline Time since hospital admission, days & $30 \pm 15$ & $22 \pm 18$ & 50.3 & $30 \pm 15$ & $28 \pm 19$ & 8.9 \\
\hline
\end{tabular}

${ }^{*} \pm$ Values are mean \pm SD. A value of less than $10.0 \%$ of the standardised difference indicates a negligible difference between groups. Patients are stratified in four risk groups based on predicted death at baseline, which was determined by a multivariable prediction model incorporating study cohort, APACHE-II score, cardiovascular failure, pulmonary failure and renal failure in the 24 hours before necrosectomy (details on prediction model in the online supplementary appendix $\mathrm{p} 7$ ). tWithin 24 hours before necrosectomy.

$\ddagger$ Circulatory systolic blood pressure $<90 \mathrm{~mm} \mathrm{Hg}$, despite adequate fluid resuscitation or need for inotropic catecholamine support. $\S \mathrm{PaO}_{2}<60 \mathrm{~mm} \mathrm{Hg}$, despite $\mathrm{FIO}_{2}$ of $30 \%$ or need for mechanical ventilation.

ๆCreatinine level $>177 \mu \mathrm{mol} / \mathrm{L}$ after rehydration or need for haemofiltration or haemodialysis.

**Positive microbiological culture from fine-needle aspiration before necrosectomy or from first catheter drainage before necrosectomy or from primary necrosectomy.

compared 215 patients undergoing minimally invasive surgical necrosectomy with 121 patients undergoing open necrosectomy. ${ }^{18}$ Mortality was $17 \%$ after minimally invasive surgical necrosectomy vs 30\% after open necrosectomy (OR 0.43; $95 \%$ CI 0.01 to $8.60 ; \mathrm{p}=0.06$ ). This meta-analysis, however, suffered from significant heterogeneity. Another single-centre study compared 274 patients undergoing minimally invasive surgical necrosectomy with 120 patients undergoing open necrosectomy; mortality was $15 \%$ vs $23 \%(p=0.06) .{ }^{12}$ Our study, with individual patient data, differed from these earlier studies because of its much larger sample size, and as a consequence the possibility to analyse different risk groups and to adjust for the effects of confounding and selection bias. Moreover, this study was novel in performing a head-to-head comparison of patients undergoing different methods of necrosectomy, in contrast to a previously published randomised study comparing open necrosectomy with a step-up approach (ie, catheter drainage followed, if necessary, by minimally invasive necrosectomy) ${ }^{15}$ and a recently finished trial comparing an endoscopic step-up approach with a surgical step-up approach (ISRCTN09186711).

How can the lower death rates after minimally invasive necrosectomy be explained? It is well known that, in various diseases, minimally invasive surgical techniques induce less surgical stress and thereby lead to a lower systemic proinflammatory response compared with open surgery. ${ }^{36} 37$ This was also demonstrated in necrotising pancreatitis: in the only randomised trial that compared endoscopic necrosectomy with surgical necrosectomy (a total of 20 patients), endoscopic necrosectomy reduced the levels of the proinflammatory cytokine interleukin (IL)-6 during the 7 days after the procedure. ${ }^{17}$ The more pronounced proinflammatory response invoked by open necrosectomy may facilitate organ failure or worsen pre-existing organ failure, especially in patients who are already suffering from a severe inflammatory condition such as necrotising pancreatitis. ${ }^{15}$ This seems of particular importance because organ failure is the main determinant for mortality in patients with necrotising pancreatitis, especially in the presence of infected necrosis. ${ }^{38}$ The same trial that demonstrated lower levels of IL-6 after endoscopic necrosectomy also showed lower rates of postprocedure multiple organ failure. ${ }^{17} \mathrm{~A}$ reduction in multiple organ failure with less surgical stress was also seen in another randomised trial that compared primary catheter drainage with open necrosectomy in 88 patients with necrotising pancreatitis. ${ }^{15}$ In contrast with these previous trials, ${ }^{1517}$ we did not study the rate of organ failure as a surrogate outcome. Our study was designed to evaluate the most relevant clinical endpoint of mortality, with a sufficiently large number of patients, even in the subgroups of the most severely ill patients.

Our results suggest that patients with necrotising pancreatitis who are severely ill should undergo minimally invasive surgical or endoscopic necrosectomy instead of open necrosectomy, given the expertise in these minimally invasive techniques is available. If the expertise is absent and the patient is clinically unfit for transport to a tertiary referral centre, open necrosectomy may still be acceptable. In the propensity score-matched analysis, we did not find significantly lower death rates in the low-risk and intermediate-risk groups. These patients, who are in a relatively stable clinical condition, seem capable of sustaining the larger surgical stress and proinflammatory hit induced by open necrosectomy. Another explanation may be that, due to their lower a priori risk of death, the subgroup of less severely ill patients was too small to detect a difference in death between methods of necrosectomy. This is supported by the wide $95 \%$ CIs observed in these groups (figure 1). One could therefore argue that open necrosectomy is still a reasonable treatment option in these patients. However, other reasons to prefer minimally invasive necrosectomy techniques 
Table 2 Baseline characteristics before and after propensity score matching of patients undergoing endoscopic necrosectomy or open necrosectomy*

\begin{tabular}{|c|c|c|c|c|c|c|}
\hline \multirow[t]{2}{*}{ Characteristics } & \multicolumn{3}{|c|}{ Before matching } & \multicolumn{3}{|l|}{ After matching } \\
\hline & $\begin{array}{l}\text { Endoscopic } \\
\text { necrosectomy } \\
(\mathrm{n}=31)\end{array}$ & $\begin{array}{l}\text { Open } \\
\text { necrosectomy } \\
(\mathrm{n}=377)\end{array}$ & $\begin{array}{l}\text { Standardised } \\
\text { difference (\%) }\end{array}$ & $\begin{array}{l}\text { Endoscopic } \\
\text { necrosectomy } \\
(\mathrm{n}=29)\end{array}$ & $\begin{array}{l}\text { Open } \\
\text { necrosectomy } \\
(n=29)\end{array}$ & $\begin{array}{l}\text { Standardised } \\
\text { difference (\%) }\end{array}$ \\
\hline \multicolumn{7}{|l|}{ Low risk of death $(<5 \%)$} \\
\hline Male sex, n (\%) & $22(71)$ & $276(73)$ & 5.3 & $21(72)$ & $21(72)$ & 1.4 \\
\hline Age & $39 \pm 11$ & $44 \pm 13$ & 49.4 & $39 \pm 11$ & $40 \pm 10$ & 1.1 \\
\hline \multicolumn{7}{|l|}{ Cause, n (\%) } \\
\hline Gallstones & $10(32)$ & $111(29)$ & 6.3 & $8(28)$ & $8(28)$ & 0.3 \\
\hline Alcohol & $8(26)$ & $177(47)$ & 45.2 & $8(28)$ & $8(28)$ & 0.3 \\
\hline Other & $13(42)$ & $89(24)$ & 39.8 & $13(44)$ & $13(44)$ & 0.1 \\
\hline APACHE-II score $†$ & $3.3 \pm 2.9$ & $7.7 \pm 4.2$ & 124.8 & $3.7 \pm 2.9$ & $3.1 \pm 2.8$ & 10.0 \\
\hline Cardiovascular failure, $\mathrm{n}(\%) \dagger \ddagger$ & 0 & $7(2)$ & 19.5 & 0 & 0 & 0 \\
\hline Pulmonary failure, $\mathrm{n}(\%)+\S$ & 0 & $30(8)$ & 42.4 & 0 & 0 & 0 \\
\hline Renal failure, $\mathrm{n}(\%)+\uparrow$ & 0 & $10(3)$ & 23.4 & 0 & 0 & 0 \\
\hline Documented infected necrosis, $\mathrm{n}(\%)^{* *}$ & $12(39)$ & $279(74)$ & 76.5 & $11(38)$ & $12(41)$ & 8.4 \\
\hline Tertiary referral, $\mathrm{n}(\%)$ & $25(81)$ & $205(55)$ & 57.8 & $23(79)$ & $23(79)$ & 3.2 \\
\hline \multirow[t]{2}{*}{ Time since hospital admission, days } & $88 \pm 118$ & $51 \pm 133$ & 29.7 & $89 \pm 121$ & $86 \pm 203$ & 7.6 \\
\hline & $\begin{array}{l}\text { Endoscopic } \\
\text { necrosectomy } \\
(n=120)\end{array}$ & $\begin{array}{l}\text { Open } \\
\text { necrosectomy } \\
(n=343)\end{array}$ & $\begin{array}{l}\text { Standardised } \\
\text { difference (\%) }\end{array}$ & $\begin{array}{l}\text { Endoscopic } \\
\text { necrosectomy } \\
(n=72)\end{array}$ & $\begin{array}{l}\text { Open } \\
\text { necrosectomy } \\
(n=72)\end{array}$ & $\begin{array}{l}\text { Standardised } \\
\text { difference (\%) }\end{array}$ \\
\hline \multicolumn{7}{|l|}{ Intermediate risk of death ( $\geq 5 \%$ to $<15 \%)$} \\
\hline Male sex, $n(\%)$ & $85(71)$ & $229(67)$ & 9.2 & $49(68)$ & $48(67)$ & 2.4 \\
\hline Age & $50 \pm 14$ & $53 \pm 14$ & 2.1 & $53 \pm 14$ & $54 \pm 13$ & 3.6 \\
\hline \multicolumn{7}{|l|}{ Cause, (\%) } \\
\hline Gallstones & $57(48)$ & $139(40)$ & 14.3 & $33(46)$ & $34(47)$ & 1.2 \\
\hline Alcohol & $29(24)$ & $119(35)$ & 23.4 & $20(28)$ & $21(29)$ & 3.1 \\
\hline Other & $34(28)$ & $85(25)$ & 8.0 & $19(26)$ & $17(24)$ & 4.7 \\
\hline APACHE-II score $†$ & $6.5 \pm 3.1$ & $10.0 \pm 4.1$ & 96.7 & $7.4 \pm 2.8$ & $7.4 \pm 3.6$ & 0.5 \\
\hline Cardiovascular failure, $(\%) \dagger \ddagger$ & 0 & $65(19)$ & 68.1 & 0 & 0 & 0 \\
\hline Pulmonary failure, $\mathrm{n}(\%)+\S$ & $1(1)$ & $113(33)$ & 94.5 & $1(1)$ & $1(1)$ & 6.7 \\
\hline Renal failure, $\mathrm{n}(\%)+\emptyset$ & 0 & $42(12)$ & 52.9 & 0 & 0 & 0 \\
\hline Documented infected necrosis, $\mathrm{n}(\%)^{* *}$ & $59(49)$ & $270(79)$ & 64.3 & $46(64)$ & $47(65)$ & 3.1 \\
\hline Tertiary referral, $\mathrm{n}(\%)$ & $80(67)$ & $208(61)$ & 12.8 & $46(64)$ & $45(63)$ & 1.0 \\
\hline \multirow[t]{2}{*}{ Time since hospital admission, days } & $48 \pm 51$ & $30 \pm 27$ & 42.9 & $36 \pm 30$ & $37 \pm 29$ & 2.9 \\
\hline & $\begin{array}{l}\text { Endoscopic } \\
\text { necrosectomy } \\
(n=133)\end{array}$ & $\begin{array}{l}\text { Open } \\
\text { necrosectomy } \\
(n=225)\end{array}$ & $\begin{array}{l}\text { Standardised } \\
\text { difference (\%) }\end{array}$ & $\begin{array}{l}\text { Endoscopic } \\
\text { necrosectomy } \\
(n=40)\end{array}$ & $\begin{array}{l}\text { Open } \\
\text { necrosectomy } \\
(n=40)\end{array}$ & $\begin{array}{l}\text { Standardised } \\
\text { difference (\%) }\end{array}$ \\
\hline \multicolumn{7}{|l|}{ High risk of death ( $\geq 15 \%$ to $<35 \%$ ) } \\
\hline Male sex, n (\%) & $68(51)$ & $140(62)$ & 22.9 & $23(58)$ & $25(63)$ & 9.2 \\
\hline Age & $59 \pm 12$ & $58 \pm 14$ & 6.0 & $60 \pm 13$ & $60 \pm 14$ & 1.5 \\
\hline \multicolumn{7}{|l|}{ Cause, $n(\%)$} \\
\hline Gallstones & $66(50)$ & $88(39)$ & 21.5 & $16(40)$ & $18(45)$ & 5.1 \\
\hline Alcohol & $27(20)$ & $81(36)$ & 35.8 & $13(32)$ & $12(30)$ & 3.5 \\
\hline Other & $40(30)$ & $56(25)$ & 11.7 & $11(28)$ & $10(25)$ & 2.8 \\
\hline APACHE-II score $†$ & $8.9 \pm 2.9$ & $12.8 \pm 4.2$ & 105.2 & $10.6 \pm 2.8$ & $10.5 \pm 2.7$ & 5.4 \\
\hline Cardiovascular failure, $\mathrm{n}(\%) \dagger \ddagger$ & $11(8)$ & $98(44)$ & 88.2 & $9(23)$ & $10(25)$ & 4.5 \\
\hline Pulmonary failure, $\mathrm{n}(\%)+\S$ & $7(5)$ & $145(65)$ & 158.9 & $7(18)$ & $7(18)$ & 1.5 \\
\hline Renal failure, $\mathrm{n}(\%)+\uparrow$ & $2(2)$ & $65(29)$ & 82.6 & $2(5)$ & $3(8)$ & 6.2 \\
\hline Documented infected necrosis, $\mathrm{n}(\%)^{* *}$ & $76(57)$ & $182(81)$ & 53.3 & $32(80)$ & $32(80)$ & 2.7 \\
\hline Tertiary referral, $\mathrm{n}(\%)$ & $96(72)$ & $160(71)$ & 2.1 & $29(73)$ & $31(78)$ & 9.3 \\
\hline \multirow[t]{2}{*}{ Time since hospital admission, days } & $59 \pm 84$ & $24 \pm 19$ & 57.7 & $27 \pm 15$ & $27 \pm 20$ & 3.5 \\
\hline & $\begin{array}{l}\text { Endoscopic } \\
\text { necrosectomy } \\
(n=62)\end{array}$ & $\begin{array}{l}\text { Open } \\
\text { necrosectomy } \\
(n=222)\end{array}$ & $\begin{array}{l}\text { Standardised } \\
\text { difference (\%) }\end{array}$ & $\begin{array}{l}\text { Endoscopic } \\
\text { necrosectomy } \\
(n=57)\end{array}$ & $\begin{array}{l}\text { Open } \\
\text { necrosectomy } \\
(n=57)\end{array}$ & $\begin{array}{l}\text { Standardised } \\
\text { difference (\%) }\end{array}$ \\
\hline \multicolumn{7}{|l|}{ Very high risk of death $(\geq 35 \%)$} \\
\hline Male sex, n (\%) & $40(65)$ & $146(66)$ & 2.3 & $37(65)$ & $35(61)$ & 5.0 \\
\hline Age & $64 \pm 14$ & $62 \pm 14$ & 10.9 & $63 \pm 14$ & $63 \pm 14$ & 0.4 \\
\hline
\end{tabular}




\section{Endoscopy}

Table 2 Continued

\begin{tabular}{|c|c|c|c|c|c|c|}
\hline $\begin{array}{r}\text { Characteristics } \\
\text { Cause, n (\%) }\end{array}$ & \multicolumn{3}{|c|}{ Before matching } & \multicolumn{3}{|c|}{ After matching } \\
\hline Gallstones & $37(60)$ & $99(44)$ & 30.6 & $34(59)$ & $33(58)$ & 0.6 \\
\hline Alcohol & $14(22)$ & $66(30)$ & 16.1 & $14(25)$ & $13(23)$ & 4.6 \\
\hline Other & $11(18)$ & $57(26)$ & 19.7 & $9(16)$ & $11(19)$ & 5.3 \\
\hline APACHE-II scoret & $16.0 \pm 6.2$ & $16.6 \pm 5.3$ & 11.9 & $16.2 \pm 6.4$ & $16.4 \pm 5.3$ & 2.8 \\
\hline Cardiovascular failure, $\mathrm{n}(\%) \dagger \ddagger$ & $33(53)$ & $179(81)$ & 60.5 & $33(58)$ & $34(60)$ & 4.3 \\
\hline Pulmonary failure, $\mathrm{n}(\%)+\S$ & $35(56)$ & $182(82)$ & 57.6 & $35(61)$ & $34(60)$ & 1.3 \\
\hline Renal failure, $\mathrm{n}(\%)+\uparrow$ & $18(29)$ & $123(55)$ & 55.3 & $18(32)$ & $16(28)$ & 6.2 \\
\hline Documented infected necrosis, $\mathrm{n}(\%)^{* *}$ & $50(81)$ & $154(69)$ & 26.8 & $46(81)$ & $46(81)$ & 0.2 \\
\hline Tertiary referral, $\mathrm{n}(\%)$ & $48(77)$ & $168(76)$ & 3.8 & $45(79)$ & $43(76)$ & 6.7 \\
\hline Time since hospital admission, days & $36 \pm 24$ & $22 \pm 18$ & 65.0 & $33 \pm 17$ & $33 \pm 22$ & 2.9 \\
\hline
\end{tabular}

${ }^{*} \pm$ Values are mean \pm SD. A value of less than $10.0 \%$ of the standardised difference indicates a negligible difference between groups. Patients are stratified in four risk groups based on predicted death at baseline, which was determined by a multivariable prediction model incorporating study cohort, APACHE-II score, cardiovascular failure, pulmonary failure and renal failure in the 24 hours before necrosectomy (details on prediction model in the online supplementary appendix p7).

tWithin 24 hours before necrosectomy.

‡Circulatory systolic blood pressure $<90 \mathrm{~mm} \mathrm{Hg}$, despite adequate fluid resuscitation or need for inotropic catecholamine support.

$\S \mathrm{PaO}_{2}<60 \mathrm{~mm} \mathrm{Hg}$, despite $\mathrm{FIO}_{2}$ of $30 \%$ or need for mechanical ventilation.

ๆCreatinine level $>177 \mu \mathrm{mol} / \mathrm{L}$ after rehydration or need for haemofiltration or haemodialysis.

**Positive microbiological culture from fine-needle aspiration before necrosectomy or from first catheter drainage before necrosectomy or from primary necrosectomy.

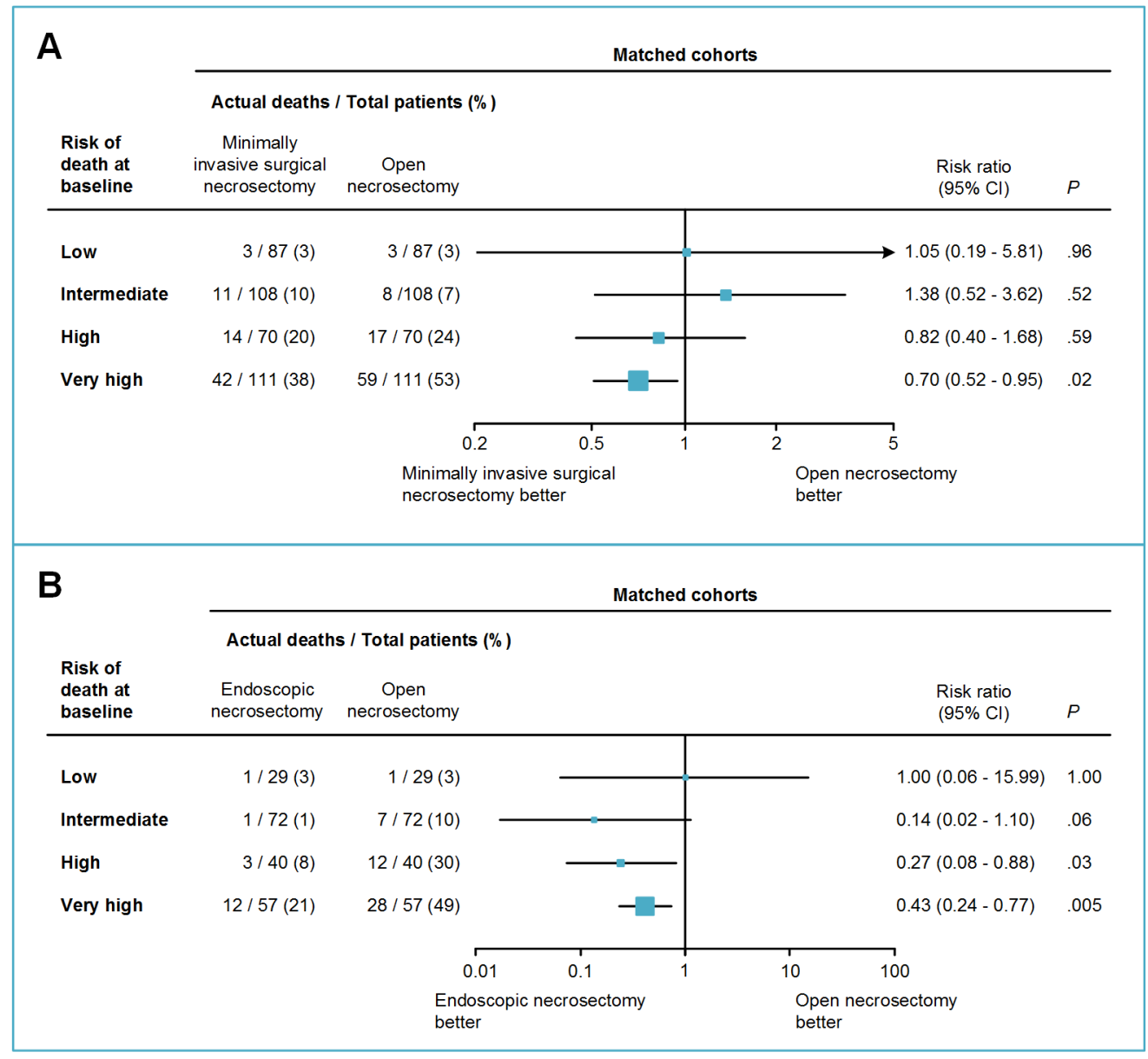

Figure 1 Death rates in patients undergoing minimally invasive surgical necrosectomy and endoscopic necrosectomy as compared with patients undergoing open necrosectomy. Shown are actual death rates / total patients (\%) for patients undergoing minimally invasive surgical necrosectomy (A) and endoscopic necrosectomy (B) as compared with patients undergoing open necrosectomy in the propensity-score matched cohorts. Patients are stratified in four risk groups based on predicted death at baseline (Low: $<5 \%$, Intermediate: $\geq 5 \%$ to $<15 \%$, High: $\geq 15 \%$ to $<35 \%$ and Very high: $\geq 35 \%$ ) which was determined by a multivariable prediction model incorporating study cohort (ie, to adjust for hidden confounders), age, APACHE-II score, cardiovascular failure, pulmonary failure, and renal failure in the 24 hours before necrosectomy. 
are lower rates of pancreatic fistula as shown in our study and lower rates of long-term complications such as incisional hernias and endocrine or exocrine pancreatic insufficiency. ${ }^{1517}$ To fill the existing evidential gap on clinical outcome superiority for the increasing popularity of minimally invasive necrosectomy, the primary aim of our study was to compare minimally invasive necrosectomy with open necrosectomy on the outcome in-hospital death. In our secondary analysis we compared endoscopic necrosectomy with minimally invasive surgical necrosectomy. Although endoscopic treatment is considered the least invasive necrosectomy method, we did not find a statistically significant decrease in mortality. This could be explained by a type II error. Endoscopic techniques are rapidly developing, for example with the recent introduction of lumen apposing metal stents which show promising results with high clinical success rates. ${ }^{39}$ It is therefore expected that in the evolution of necrosectomy techniques, a shift will occur from open necrosectomy to minimally invasive necrosectomy to an increase in the use of endoscopic techniques.

Our study does not have the preferred design of a randomised trial. It is therefore possible that measurement errors and hidden or unknown confounding factors, which are not accounted for in our analyses, may have influenced results. Using per-protocol predefined case record forms for data extraction and well-defined patient inclusion criteria, however, reduced the risk of measurement errors to a minimum. The included cohorts did not capture data on preoperative imaging, such as extent and location of peripancreatic necrosis on CT. These factors likely influenced the decisions to perform minimally invasive or open necrosectomy in certain patients. For instance, small and centrally located peripancreatic collections are best accessible by endoscopy, whereas collections extending to the paracolic gutter may prefer a minimally invasive surgical approach. Notably, not all patients with necrotising pancreatitis are candidates for minimally invasive techniques. A small minority of patients with extensive collections may only be suitable for an open surgical approach. Also, the time period in which necrosectomy was performed may have introduced unknown confounders (eg, supportive treatment on the intensive care unit may have improved over the years). As all three necrosectomy methods were performed in the most recent years (1998 and onward), overlap was judged to be sufficient for adjustment for year of necrosectomy in our first main (multivariable regression) analyses. This does not exclude all risks of lack of overlap in the regression analysis, however, because it may have led to extrapolation of the results from previous years to newer years. The insufficient overlap in the variable 'year of necrosectomy' between minimally invasive necrosectomy methods and open necrosectomy precluded the inclusion of year of necrosectomy as a factor in the propensity score matching. Too many patients from the control group (ie, open necrosectomy) would have been excluded, which would have led to a significant loss of matched pairs. We performed our study in the largest known cohort of patients undergoing necrosectomy for necrotising pancreatitis. In our analyses, we adjusted for important factors widely recognised as being associated with death. Unfortunately, the risk of residual confounding, which can only be eliminated by a randomised design, remains apparent. A randomised trial with a sample size large enough to detect a difference in mortality will, however, be very difficult to realise and no such trial is currently planned. Future randomised studies concentrating on patient-oriented outcomes such as health-related quality of life and hospital stay may serve as a valuable alternative. Until these are available, large observational studies, despite their inherent risk of persisting bias, yield the best available evidence to guide clinical decision making in this severe and complex disease. Because patients from 51 hospitals across 8 countries and 3 continents were included in this study, we believe our results are generalisable to patient populations with necrotising pancreatitis.

In conclusion, among severely ill patients with necrotising pancreatitis, minimally invasive surgical necrosectomy and endoscopic necrosectomy are associated with reduced death rates compared with open necrosectomy.

\section{Author affiliations}

${ }^{1}$ Department of Gastroenterology, Academic Medical Center, Amsterdam, The Netherlands

${ }^{2}$ Department of Surgery, Academic Medical Center, Amsterdam, The Netherlands ${ }^{3}$ Department of Research and Development, St Antonius Hospital, Nieuwegein, The Netherlands

${ }^{4}$ Department of Surgery, University Medical Center Utrecht, Utrecht ${ }^{5}$ Department of Gastroenterology and Hepatology, University of North Carolina, Chapel Hill, North Carolina, USA

${ }^{6}$ Department of Surgery, University of Ulm, Ulm, Germany

${ }^{7}$ Department of Radiology, St Antonius Hospital, Nieuwegein, The Netherlands

${ }^{8}$ Department of Gastroenterology and Hepatology, Erasmus Medical Center, Rotterdam, The Netherlands

${ }^{9}$ West of Scotland Pancreatic Unit, Glasgow Royal Infirmary, Glasgow, UK

${ }^{10}$ Department of Surgery, Freeman Hospital, Newcastle upon Tyne, UK

${ }^{11}$ Department of Surgery, Hospital Clementino Fraga Filho, Federal University of Rio de Janeiro, Rio de Janeiro, Brazil

${ }^{12}$ Department of Internal Medicine, Oldenburg Municipal Hospital, Oldenburg, Germany

${ }^{13}$ Clinical Research Unit, Academic Medical Center, Amsterdam, The Netherlands ${ }^{14}$ Department of Gastrointestinal Surgery, Jaslok Hospital and Research Center,

Mumbai, India

${ }^{15}$ Department of Surgery, Massachusetts General Hospital, Harvard Medical School, Boston, Massachusetts, USA

${ }^{16}$ Department of Surgery, University of Szeged, Szeged, Hungary

${ }^{17}$ Department of Gastroenterology, University of Minnesota, Minneapolis, Minnesota, USA

${ }^{18}$ Department of Gastroenterology and Hepatology, Dartmouth-Hitchcock Medical

Center, One Medical Center Drive, Lebanon, New Hampshire, USA

${ }^{19}$ Department of Surgery, Radboud University Medical Center, Nijmegen, The

Netherlands

${ }^{20}$ Operating Rooms-Evidence Based Surgery, Radboud University Medical Center,

Nijmegen, The Netherlands

${ }^{21}$ Orthopaedic Research Lab, Radboud Institute for Health Sciences, Radboud University Medical Center, Nijmegen, The Netherlands

${ }^{22}$ Clinical Directorate of General Surgery, National Institutes of Health Research Liverpool Pancreas Biomedical Research Unit, Royal Liverpool and Broadgreen

University Hospitals NHS Trust, Liverpool, UK

${ }^{23}$ Department of Surgery, Petz-Aladár Teaching Hospital, Györ, Hungary

${ }^{24}$ Department of Surgery, University of Edinburgh, Edinburgh, UK

${ }^{25}$ Department of Surgery, University of Rostock, Rostock, Germany

${ }^{26}$ Department of Interdisciplinary Endoscopy, University Hospital Hamburg-Eppendorf, Hamburg, Germany

${ }^{27}$ Department of Surgery, Manchester Royal Infirmary, Manchester, UK

${ }^{28}$ Department of Surgery, University of Washington, Seattle, USA

${ }^{29}$ Department of Surgery, St Antonius Hospital, Nieuwegein, The Netherlands

Correction notice This article has been corrected since it published Online First. The footnotes in tables 1 and 2 have been corrected.

Contributors Study concept and design: RAH, OJB, SvB, MGB, MAB, MGD, HGG, $\mathrm{GH}, \mathrm{KDH}, \mathrm{HCvS}$. Acquisition of data: OJB, MGB, THB, HGB, MAB, TLB, MJB, SvB, RC, RMC, DC, BD, ND, GF, PJF, CF-dC, PF, MLF, TBG, HvG, HGG, RAH, RL, CJM, MPP, JPN, AO, RWP, MR, BR, TR, HS, AKS, KDH, HCVS. Analysis and interpretation of data: OJB, SvB, MGD, GH, RAH, MR, HCVS. Drafting of the manuscript: OJB, SvB, RAH, $\mathrm{KDH}, \mathrm{HCVS}$. Critical revision of the manuscript for important intellectual content: all authors. Statistical analysis: SvB, MGD, GH, RAH, HCvS. Study supervision: HCvS.

Funding Dutch Digestive Disease Foundation. Role of the sponsor: The sponsor did not play any role in concept and design, statistical analysis, interpretation of the data, writing of the manuscript or decision to submit the manuscript. The researchers were fully independent from the funder.

Competing interests All authors declare no support from any organisation for the submitted work, no financial relationships with any organisation that might have an interest in the submitted work in the previous 3 years, and no other relationships or activities that could appear to have influenced the submitted work. 
Ethics approval The institutional review boards of the participating centres approved study protocols, if appropriate.

Provenance and peer review Not commissioned; externally peer reviewed.

(c) Article author(s) (or their employer(s) unless otherwise stated in the text of the article) 2018. All rights reserved. No commercial use is permitted unless otherwise expressly granted.

\section{REFERENCES}

1 Banks PA, Bollen TL, Dervenis C, et al. Classification of acute pancreatitis--2012: revision of the Atlanta classification and definitions by international consensus. Gut 2013;62:102-11.

2 Lankisch PG, Apte M, Banks PA. Acute pancreatitis. Lancet 2015:386:85-96.

3 Working Group IAP/APA acute pancreatitis guidelines. IAP/APA evidence-based guidelines for the management of acute pancreatitis. Pancreatology 2013;13:e1-15.

4 Tenner S, Baillie J, DeWitt J, et al. American College of Gastroenterology guideline: management of acute pancreatitis. Am J Gastroenterol 2013;108:1400-15.

5 Howard TJ, Patel JB, Zyromski N, et al. Declining morbidity and mortality rates in the surgical management of pancreatic necrosis. J Gastrointest Surg 2007;11:43-9.

6 Mofidi R, Lee AC, Madhavan KK, et al. Prognostic factors in patients undergoing surgery for severe necrotizing pancreatitis. World J Surg 2007;31:2002-7.

7 Seifert H, Biermer M, Schmitt W, et al. Transluminal endoscopic necrosectomy after acute pancreatitis: a multicentre study with long-term follow-up (the GEPARD Study). Gut 2009;58:1260-6.

8 Horvath K, Freeny P, Escallon J, et al. Safety and efficacy of video-assisted retroperitoneal debridement for infected pancreatic collections: a multicenter, prospective, single-arm phase 2 study. Arch Surg 2010;145:817-25.

9 van Santvoort HC, Bakker OJ, Bollen TL, et al. A conservative and minimally invasive approach to necrotizing pancreatitis improves outcome. Gastroenterology 2011;141:1254-63.

10 Gardner TB, Coelho-Prabhu N, Gordon SR, et al. Direct endoscopic necrosectomy for the treatment of walled-off pancreatic necrosis: results from a multicenter U.S. series. Gastrointest Endosc 2011;73:718-26.

11 Madenci AL, Michailidou M, Chiou G, et al. A contemporary series of patients undergoing open debridement for necrotizing pancreatitis. Am J Surg 2014;208:324-31.

12 Gomatos IP, Halloran CM, Ghaneh P, et al. Outcomes from minimal access retroperitoneal and open pancreatic necrosectomy in 394 patients with necrotizing pancreatitis. Ann Surg 2016;263:992-1001.

13 Mier J, León EL, Castillo A, et al. Early versus late necrosectomy in severe necrotizing pancreatitis. Am J Surg 1997;173:71-5.

14 Büchler MW, Gloor B, Müller CA, et al. Acute necrotizing pancreatitis: treatment strategy according to the status of infection. Ann Surg 2000;232:619-26.

15 van Santvoort HC, Besselink MG, Bakker OJ, et al. A step-up approach or open necrosectomy for necrotizing pancreatitis. N Engl J Med 2010;362:1491-502.

16 Makhija R, Kingsnorth AN. Cytokine storm in acute pancreatitis. J Hepatobiliary Pancreat Surg 2002;9:401-10.

17 Bakker OJ, van Santvoort HC, van Brunschot S, et al. Endoscopic transgastric vs surgical necrosectomy for infected necrotizing pancreatitis: a randomized trial. JAMA 2012;307:1053-61.

18 Cirocchi R, Trastulli S, Desiderio J, et al. Minimally invasive necrosectomy versus conventional surgery in the treatment of infected pancreatic necrosis: a systematic review and a meta-analysis of comparative studies. Surg Laparosc Endosc Percutan Tech 2013;23:8-20.
19 Babu BI, Sheen AJ, Lee SH, et al. Open pancreatic necrosectomy in the multidisciplinary management of postinflammatory necrosis. Ann Surg 2010;251:783-6.

20 Zyromski NJ. Necrotizing pancreatitis 2010: an unfinished odyssey. Ann Surg 2010;251:794-5.

21 Rau B, Bothe A, Beger HG. Surgical treatment of necrotizing pancreatitis by necrosectomy and closed lavage: changing patient characteristics and outcome in a 19-year, single-center series. Surgery 2005;138:28-39.

22 Farkas G, Márton J, Mándi Y, et al. Surgical management and complex treatment of infected pancreatic necrosis: 18-year experience at a single center. J Gastrointest Surg 2006;10:278-85.

23 Oláh A, Belágyi T, Bartek P, et al. Alternative treatment modalities of infected pancreatic necrosis. Hepatogastroenterology 2006;53:603-7.

24 Rodriguez JR, Razo A0, Targarona J, et al. Debridement and closed packing for sterile or infected necrotizing pancreatitis: insights into indications and outcomes in 167 patients. Ann Surg 2008;247:294-9.

25 Coelho D, Ardengh JC, Eulálio JM, et al. Management of infected and sterile pancreatic necrosis by programmed endoscopic necrosectomy. Dig Dis 2008;26:364-9.

26 Raraty MG, Halloran CM, Dodd S, et al. Minimal access retroperitoneal pancreatic necrosectomy: improvement in morbidity and mortality with a less invasive approach. Ann Surg 2010;251:787-93.

27 Doctor N, Philip S, Gandhi V, et al. Analysis of the delayed approach to the management of infected pancreatic necrosis. World J Gastroenterol 2011;17:366-71.

28 von Elm E, Altman DG, Egger M, et al. The strengthening the Reporting of Observational studies in Epidemiology (STROBE) statement: guidelines for reporting observational studies. Lancet 2007;370:1453-7.

29 Stewart LA, Clarke M, Rovers $M$, et al. Preferred Reporting items for systematic review and Meta-Analyses of individual participant data: the PRISMA-IPD statement. JAMA 2015;313:1657-65.

30 Salas M, Hofman A, Stricker BH. Confounding by indication: an example of variation in the use of epidemiologic terminology. Am J Epidemiol 1999;149:981-3.

31 Textor J, Hardt J, Knüppel S. DAGitty: A graphical tool for analyzing causal diagrams. Epidemiology 2011;22:745.

32 Knaus WA, Zimmerman JE, Wagner DP, et al. APACHE-acute physiology and chronic health evaluation: a physiologically based classification system. Crit Care Med 1981;9:591-7.

33 Mihaylova B, Emberson J, Blackwell L, et al. The effects of lowering LDL cholesterol with statin therapy in people at low risk of vascular disease: meta-analysis of individual data from 27 randomised trials. Lancet 2012;380:581-90.

34 Dellinger EP, Forsmark CE, Layer $\mathrm{P}$, et al. Determinant-based classification of acute pancreatitis severity: an international multidisciplinary consultation. Ann Surg 2012;256:875-80.

35 Austin PC. An introduction to propensity score methods for reducing the effects of confounding in observational studies. Multivariate Behav Res 2011;46:399-424.

36 Wichmann MW, Hüttl TP, Winter $\mathrm{H}$, et al. Immunological effects of laparoscopic vs open colorectal surgery: a prospective clinical study. Arch Surg 2005;140:692-7.

37 Nguyen NT, Goldman CD, Ho HS, et al. Systemic stress response after laparoscopic and open gastric bypass. J Am Coll Surg 2002;194:557-66.

38 Petrov MS, Shanbhag S, Chakraborty M, et al. Organ failure and infection of pancreatic necrosis as determinants of mortality in patients with acute pancreatitis. Gastroenterology 2010;139:813-20.

39 Sharaiha RZ, Tyberg A, Khashab MA, et al. Endoscopic therapy with Lumen-apposing metal stents is safe and effective for patients with pancreatic Walled-off necrosis. Clin Gastroenterol Hepatol 2016;14:1797-803. 


\section{GUT}

Minimally invasive and endoscopic versus open necrosectomy for necrotising pancreatitis: a pooled analysis of individual data for 1980 patients

Sandra van Brunschot, Robbert A Hollemans, Olaf J Bakker, Marc G Besselink, Todd H Baron, Hans G Beger, Marja A Boermeester, Thomas L Bollen, Marco J Bruno, Ross Carter, Jeremy J French, Djalma Coelho, Björn Dahl, Marcel G Dijkgraaf, Nilesh Doctor, Peter J Fagenholz, Gyula Farkas, Carlos Fernandez del Castillo, Paul Fockens, Martin L Freeman, Timothy B Gardner, Harry van Goor, Hein G Gooszen, Gerjon Hannink, Rajiv Lochan, Colin J McKay, John P Neoptolemos, Atilla Oláh, Rowan W Parks, Miroslav P Peev, Michael Raraty, Bettina Rau, Thomas Rösch, Maroeska Rovers, Hans Seifert, Ajith K Siriwardena, Karen D Horvath and Hjalmar C van Santvoort

Gut2018 67: 697-706 originally published online August 3, 2017 doi: 10.1136/gutjnl-2016-313341

Updated information and services can be found at: http://gut.bmj.com/content/67/4/697

\section{References \\ Email alerting service}

\section{These include:}

This article cites 39 articles, 2 of which you can access for free at: http://gut.bmj.com/content/67/4/697\#ref-list-1

Receive free email alerts when new articles cite this article. Sign up in the box at the top right corner of the online article.

\section{Notes}

To request permissions go to:

http://group.bmj.com/group/rights-licensing/permissions

To order reprints go to:

http://journals.bmj.com/cgi/reprintform

To subscribe to BMJ go to:

http://group.bmj.com/subscribe/ 